\title{
The evaluation of psychiatric drug therapy on oral lichen planus patients with psychiatric disorders
}

\author{
Zahra Delavarian ${ }^{1}$, Abbas Javadzade-Bolouri ${ }^{2}$, Zohreh Dalirsani ${ }^{3}$, Hamid-Reza Arshadi ${ }^{4}$, Hamid Toofani- \\ Asl 5
}

${ }^{1}$ DS, MSc, Associate Professor of Oral Medicine, Dental Research Center of Mashhad University of Medical Sciences, Department of Oral Medicine of Mashhad Dental School, Mashhad, Iran

${ }^{2}$ DDS, MSc, Associate Professor of Oral Medicine, Dental Research Center of Mashhad University of Medical Sciences, Department of Oral Medicine of Mashhad Dental School, Mashhad, Iran

${ }^{3}$ DDS, MSc, Assistant Professor of Oral Medicine, Dental Research Center of Mashhad University of Medical Sciences, Department of Oral Medicine of Mashhad Dental School, Mashhad, Iran

${ }^{4}$ MS, Assistant Professor, Department of psychology, Mashhad Medical School, Mashhad, Iran

${ }^{5}$ MS, Associate Professor, Department of psychology, Mashhad Medical School, Mashhad, Iran

Correspondence:

Department of Oral Medicine,

Mashhad dental school

Vakil abad street, Mashhad

Khorasan Razavi,

Postal code: 91735, Mashhad, Iran

zdalirsani@gmail.com

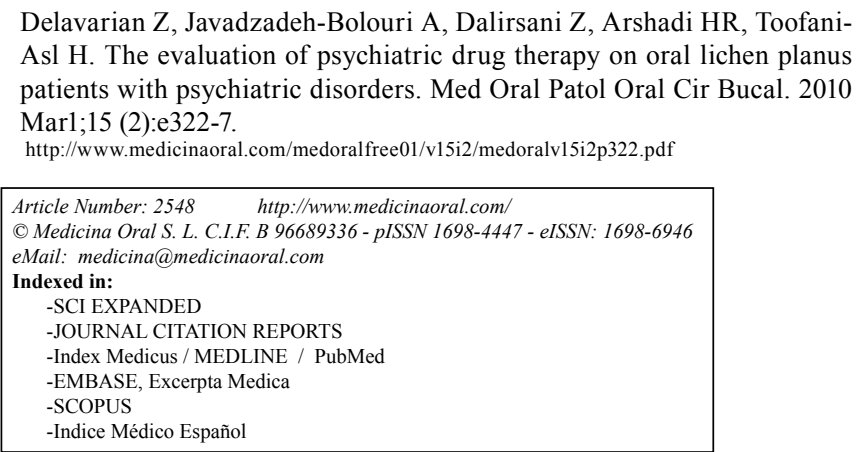

\begin{abstract}
Objectives: Current treatments of oral lichen planus are palliative, not curative. Because psychiatric disorders significantly influence the development and severity of oral lichen planus, the use of psychiatric drug therapy may be an adjunct in treatment. The purpose of this study was to determine the efficacy of drug therapy of psychiatric disorders in oral lichen planus. Study design: Our controlled clinical study consisted of forty-six patients with oral lichen planus and psychiatric disorders who were randomly divided into two groups. Both groups were given topical corticosteroids and the study group received additional psychiatric drug therapy. Patients were monitored for a period of 6 months. Response to treatment was evaluated in each group and was compared with the other group using Mann-Whitney tests. We evaluated the correlation between psychiatric disorders and the recovery of oral lesions using Spearman's correlation coefficient analysis. Results: Decrease in the size of the lesions was significantly greater in the study group after six months, but this difference was not significant in relationship to the pain experienced and the kind of lesion. Spearman's correlation coefficient analysis demonstrated that, in the sixth month, there was a significant and direct relationship between recovery from the psychiatric disorders and response to treatment of OLP lesions, particularly as it pertained to the kind of lesion. Conclusion: The present study indicates that the combination of psychiatric drug therapy and routine treatment methods were effective in reducing the size of the lesions, but did not have any significant effect on the symptoms.
\end{abstract}

Key words: Oral, lichen planus, psychiatric disorders, anxiety disorders, drug therapy. 


\section{Introduction}

Lichen planus is a relatively common chronic mucocutaneous disease. The disease has varied prevalence in different parts of the world but generally approximately $1 \%$ of the world population suffer from skin lesions (1) and around $0.5-2.2 \%$ have the oral lesions $(1,2)$. Exact etiology of the disease is unknown, but it has been demonstrated that degeneration of the epithelial basal layer, resulting from a change in cell-mediated immune response, has a significant role in the pathogenicity of the lesion (3). Therefore, any factor that can influence the cell-mediated immune response can have a role in the development of the disease. Factors such as stress and psychological problems, especially depression and anxiety, have been mentioned as etiologic factors in lichen planus but there is still controversy concerning the role of stress as a major or minor etiologic factor in the pathogenicity of lichen planus (4-7).

The correlation of this disease and psychiatric disorders has been studied, but no research into the effect of psychiatric therapy on oral lichen planus patients has been carried out to date. In the present study we tried to evaluate psychiatric condition of our patients and the concomitant effect of the drug therapy of psychological disorders and routine treatment modalities of lichen planus on oral lesions.

\section{Material and Methods}

A randomized clinical trial study was designed to evaluate the effect of the drug therapy of psychiatric disorders on lichen planus. We filled out Special examination forms for 55 patients referring to the Oral Medicine Department in Mashad Dental School from October 2004 to December 2005 and oral lichen planus had been confirmed through clinical examination, biopsy and histopathological evaluation. Then the patients were evaluated by a psychologist. Out of 55 patients, 53 patients were diagnosed with one of the psychological disorders according to the criteria set by DSM-IV-IR. (8). We explained the study procedure to the patients; then they filled out informed written consent forms. The subjects having the inclusion criteria were chosen for the study. Inclusion criteria

1) patients with oral lichen planus (all forms) with or without skin involvement;

2) affliction with psychiatric disorders.

Exclusion criteria

1) patients exhibiting dysplasia in histopathological evaluation (1 patient);

2) patients with lichenoid reaction potential as evidenced by histopathological examination, drug intake or other predisposing conditions (5 patients);

3) patients diagnosed with acute psychosis with the potential of harming themselves or others (no patients);
4) patients who had received any medications for lichen planus during the past month (1 patient);

Forty-six patients; 31 subjects from the case group and 15 subjects from the control group were followed for 6 months.

Location, form and size of the lesions and pain sensation of each patient were recorded in the questionnaires.

The severity of the signs in lichen planus depends on the form and size of the lesions. Oral lesions were described and classified in 3 groups: (1)

1) keratotic ( reticular form, plaque form or both).

2) atrophic (atrophic lesion with or without keratotic lesion).

3) erosive-bullous (erosive or bullous lesion with or without keratotic lesion).

The oral cavity was divided into ten areas to determine the percentage of lichen planus extension in the oral cavity. These areas were: oral vestibule, alveolar mucosa, lips, buccal mucosa, oral floor, fauces, gingiva, palate and the dorsal and ventral aspects of the tongue. Therefore, the percentages of the involvement for all areas of the oral mucosa were calculated and subsequently the percentage of the involvement of the oral cavity was calculated (Fig, 1,2).

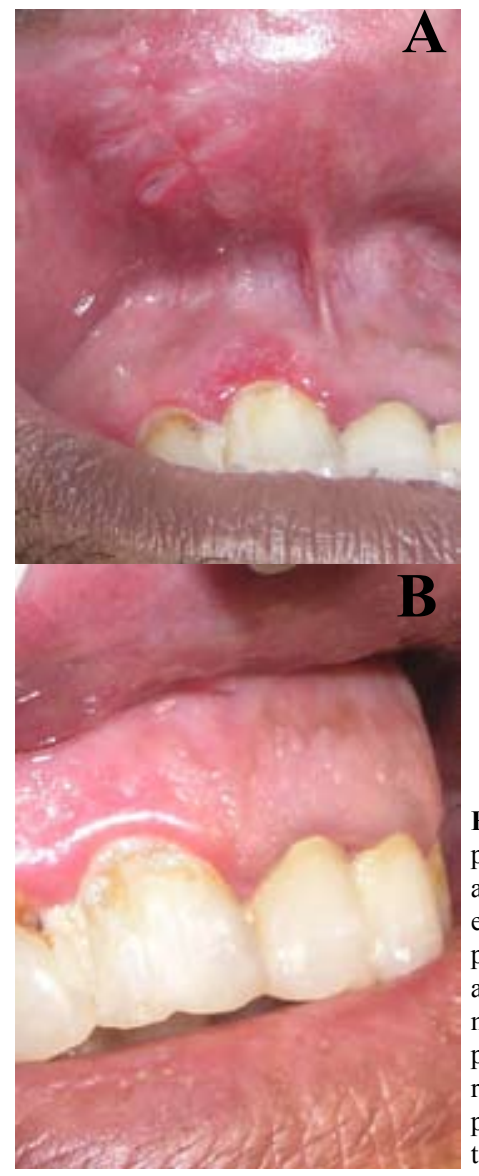

Fig. 1. patient No. 11. The patient in the case group had atrophy, erosion and moderate keratosis on the upper lip mucosa and atrophy and mild keratosis on the mucosa of the anterior upper gingival (A). Complete recovery was observed after psychiatric and routine OLP treatment (B). 


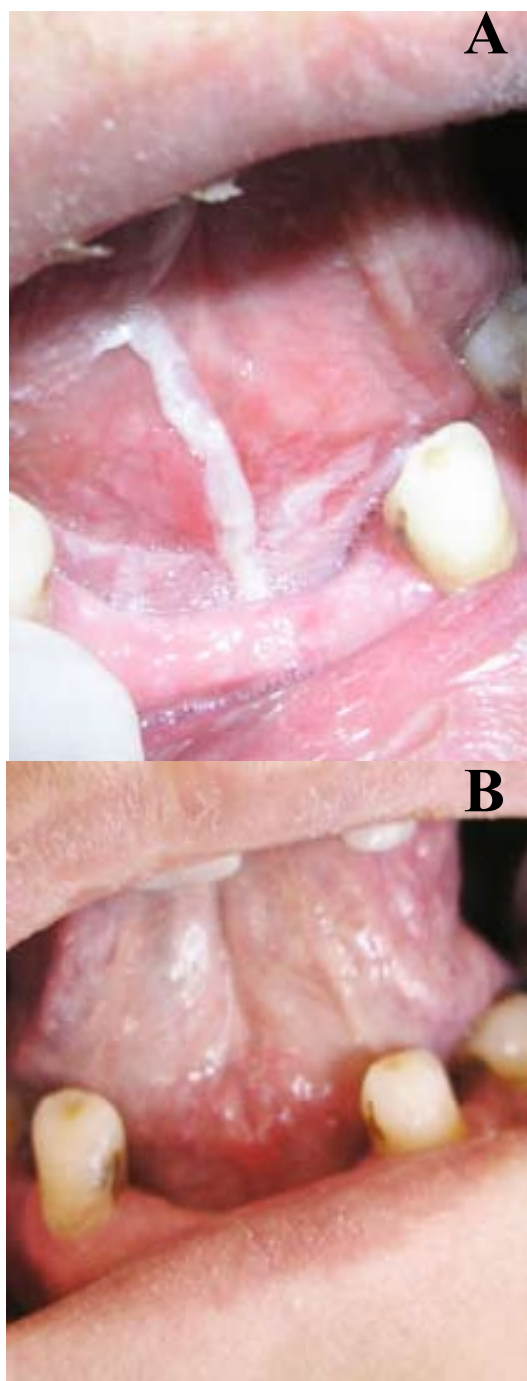

Fig. 2. patient No. 32. The patient in the case group had large ulcer and keratosis on the ventral of the tongue and floor of the mouth (A). Complete recovery was observed after psychiatric and routine OLP treatment (B).

The severity of pain and pain sensation was evaluated according to following scales:

Scale 0: no pain: $\mathrm{VAS}=0$

Scale 1: mild pain: $0<\mathrm{VAS} \leq 3.5$

Scale 2: moderate pain: $3.5<\mathrm{VAS} \leq 7$

Scale 3: severe pain: $7<\mathrm{VAS} \leq 10$ [1].

Both groups received routine treatment for oral lichen planus. This treatment regimen consisted of topical corticosteroids, mostly triamcinolone along with (antifungal) nystatin. The case group received drug therapy for psychiatric disorders in addition to the routine treatment for lichen planus. Then the patients were subjected to regular oral examinations every two weeks, carried out by an oral medicine specialist who was blinded to the treatment received by each patient, until the signs and symptoms were brought under control. The patients in the case group were evaluated for possible side effects of the medication(s) 2 weeks after the initiation of the study and afterwards were monthly examined by the psychologist, too. Treatment of patients continued until remission of signs and symptoms.

The recovery rate (response to treatment) in each patient was evaluated according to Tables 1 and 2, based on the percentage of the area involved, form of the lesion and the severity of the pain.

The psychiatric recovery of the patients has been classified in Table 3.

Table 1. Scaling of response to OLP treatment as to lesion size and extension.

\begin{tabular}{|c|c|c|}
\hline $\begin{array}{c}\text { Response to } \\
\text { treatment } \\
\text { excellent }\end{array}$ & Scale & Criteria \\
\hline good & 1 & $50 \% \leq$ recovery $<75 \%$ \\
\hline fair & 2 & $25 \% \leq$ recovery $<50 \%$ \\
\hline poor & 3 & $0 \% \leq$ recovery $<25 \%$ \\
\hline exacerbation & 4 & $\begin{array}{c}\text { increase in lesion size and } \\
\text { extension }\end{array}$ \\
\hline
\end{tabular}

Table 2. Scaling of response to OLP treatment as to the form of the lesion and severity of pain.

\begin{tabular}{|c|c|c|c|}
\hline $\begin{array}{c}\text { Response to } \\
\text { treatment }\end{array}$ & Scale & $\begin{array}{l}\text { Criteria for } \\
\text { lesion form }\end{array}$ & $\begin{array}{c}\text { Criteria for } \\
\text { severity of pain }\end{array}$ \\
\hline Excellent & 0 & $\begin{array}{c}\text { conversion of } \\
\text { scales } 1,2 \& \\
3 \text { to } 0 \\
\text { (without lesion) }\end{array}$ & $\begin{array}{c}\text { conversion of scales } \\
1,2 \& 3 \text { to } 0 \\
\text { (without pain) }\end{array}$ \\
\hline Good & 1 & $\begin{array}{l}\text { conversion of } \\
\text { scale } 3 \text { to } 1\end{array}$ & $\begin{array}{l}\text { conversion of } \\
\text { scale } 3 \text { to } 1\end{array}$ \\
\hline Fair & 2 & $\begin{array}{l}\text { conversion of } \\
\text { scale } 2 \text { to } 1 \\
\text { or conversion of } \\
\text { scale } 3 \text { to } 2\end{array}$ & $\begin{array}{c}\text { conversion of scale } \\
2 \text { to } 1 \\
\text { or } 3 \text { to } 2\end{array}$ \\
\hline Poor & 3 & $\begin{array}{l}\text { no conversion } \\
\text { in scale }\end{array}$ & no change in pain \\
\hline exacerbation & 4 & $\begin{array}{l}\text { conversion of } \\
\text { scale } 1 \text { to } 2 \\
\text { or } 3 \\
\text { or conversion of } \\
\text { scale } 2 \text { to } 3\end{array}$ & $\begin{array}{l}\text { conversion of sca- } \\
\text { le } 0 \text { to } 1 \text { or } 2 \text { or } 3 \\
\text { or conversion of } \\
\text { scale } 1 \text { to } 2 \text { or } 3\end{array}$ \\
\hline
\end{tabular}

Table 3. The classification of the psychological recovery of the patients.

\begin{tabular}{|c|c|}
\hline Scale & Response to treatment \\
\hline 0 & complete response \\
\hline 1 & good response \\
\hline 2 & little response \\
\hline 3 & no response \\
\hline
\end{tabular}


The comparison of the case and control groups regarding complete or partial response to treatment was carried out in the second and sixth months according to the codes depicted in Tables 1 and 2. The results of the two groups as to the remission of the signs and symptoms of oral lichen planus were compared using the non-parametric Mann-Whitney test.

Also, the patients in the case group were subjected to Spearman's test to be evaluated in relation to the correlation between psychological recovery and oral lesion recovery, given the size and form of the lesions and the pain sensation.

The protocol of this study was approved by the Medical Ethics Panel of Mashad Medical Sciences University and all the patients were informed of all the procedures involved in the study and all had information about the anecdotal nature of the study.

\section{Results}

The two groups were matched as to age, sex, lesion size, the severity of the pain of the lesion, number of psychiatric disorders and the type of psychiatric disorders. Our study obtained the following results:
A: Comparison of response to treatment between the patients in two groups was evaluated according to:

Size of the lesions: (Table 4) demonstrates that the patients in the case group had given a better response to lichen planus treatment, i.e. the size of the lesions had decreased to different degrees and this difference in response was significant in the sixth month $(\mathrm{P}=0.026)$.

Form of the lesions: According to Table 5, although there were differences in the response to treatment between the study group and the control group as to the conversion of severe symptomatic cases (erosive and atrophic) to milder cases (keratotic), these differences were not statistically significant in the sixth months $(\mathrm{P}=0.31)$.

Pain severity: According to Table 6, a higher proportion of patients in the case group had no pain or had mild pain in the sixth month compared to the patients in the control group. The difference was not statistically significant in the sixth months $(\mathrm{P}=0.476)$.

$\mathrm{B}$ : Correlation of response to treatment:

Spearman's correlation coefficient analysis demonstrated that, only, in the sixth month there was a significant and direct relationship between recovery from the psychiatric disorders and response to treatment of OLP lesions concerning the form of the lesions $(\mathrm{P}=0.058, \mathrm{r}=0.377)$.

Table 4. The comparison of the response to treatment between the case and control groups as to lesion size in the sixth months.

\begin{tabular}{|c|c|c|c|c|c|}
\hline \multicolumn{2}{|c|}{ Month } & \multicolumn{4}{c|}{ Six } \\
\hline \multirow{2}{*}{ Response to treatment } & \multirow{2}{*}{ Scale of response } & \multicolumn{2}{c|}{ Case } & \multicolumn{2}{c|}{ Control } \\
\cline { 3 - 6 } & & Number & Percent & Number & Percent \\
\hline excellent & 0 & 6 & 19.4 & 0 & 0.0 \\
\hline good & 1 & 8 & 25.8 & 4 & 26.7 \\
\hline fair & 2 & 7 & 22.6 & 2 & 13.3 \\
\hline poor & 3 & 8 & 25.8 & 4 & 26.7 \\
\hline exacerbation & 4 & 2 & 6.5 & 5 & 33.3 \\
\hline & Total & 31 & 100 & 15 & 100 \\
\hline
\end{tabular}

Mann-Withney test. $\mathrm{Z}=-2.22 ; \mathrm{P}=0.026$

Table 5. The comparison of response to treatment between the case and control groups as to the form of the lesions in the sixth months.

\begin{tabular}{|c|c|c|c|c|c|}
\hline \multicolumn{2}{|c|}{ Month } & \multicolumn{4}{c|}{ Six } \\
\hline \multirow{2}{*}{ Response to treatment } & \multirow{2}{*}{ Scale of response } & \multicolumn{2}{|c|}{ Case } & \multicolumn{2}{c|}{ Control } \\
\cline { 3 - 6 } & & Number & Percent & Number & Percent \\
\hline excellent & 0 & 0 & 0.0 & 0 & 0.0 \\
\hline good & 1 & 4 & 12.9 & 2 & 13.3 \\
\hline fair & 2 & 14 & 45.2 & 3 & 20.0 \\
\hline poor & 3 & 11 & 35.5 & 10 & 66.7 \\
\hline exacerbation & 4 & 2 & 6.5 & 0 & 0.0 \\
\hline & & 31 & 100 & 15 & 100 \\
\hline
\end{tabular}

Mann-Withney test. $Z=-1.002 ; P=0.31$ 
Table 6. The comparison of response to treatment between the control and case groups as to the severity of pain in the sixth months.

\begin{tabular}{|c|c|c|c|c|c|}
\hline \multicolumn{2}{|c|}{ Month } & \multicolumn{4}{|c|}{ Six } \\
\hline \multirow{2}{*}{ Response to treatment } & \multirow{2}{*}{ Scale of response } & \multicolumn{2}{|c|}{ Case } & \multicolumn{2}{|c|}{ Control } \\
\hline & & Number & Percent & Number & Percent \\
\hline excellent & 0 & 11 & 55.0 & 4 & 40.0 \\
\hline good & 1 & 1 & 5.0 & 0 & 0.0 \\
\hline fair & 2 & 3 & 15.0 & 2 & 20.0 \\
\hline poor & 3 & 3 & 15.0 & 4 & 40.0 \\
\hline exacerbation & 4 & 2 & 10.0 & 0 & 0.0 \\
\hline \multicolumn{2}{|c|}{ Total } & 20 & 100 & 10 & 100 \\
\hline
\end{tabular}

Mann-Withney test. $Z=-0.712 ; P=0.476$

\section{Discussion}

The results of the study demonstrated that a combination of psychotherapy and routine OLP treatment results in a more noticeable decrease in lesion size compared to routine OLP treatment alone.

However, here is controversy over the role of stress as a possible etiologic factor in OLP $(4,6,7)$; some studies have already been carried out on the role of psychiatric disorders and stress as etiologic factors in oral lichen planus. The vast majority of these studies have used Hamilton Anxiety Scale (HAS) and Hamilton Depression Scale (HDS) and Beck Depression Score (BDS) to compare anxiety and depression level of the patients suffering from OLP with a control group consisting of healthy subjects and some have detected a higher level of stress and depression in patients suffering from OLP $(4,7,9)$. However, these studies were not interventional studies. Contrary to these studies the present study determined the type of the psychiatric disorders through an interview with a psychologist and evaluated the effect of drug therapy of the disorders on the remission of OLP lesions.

Contrary to the vast majority of earlier studies, which have only evaluated atrophic and erosive-bullous lesions (10), we incorporated keratotic lesions, too, into our study. Keratotic lesions do not respond well to routine treatment and the evaluation of the effect of psychotherapy on these lesions is of utmost significance.

The most important consideration in this study is determining all psychotic disorders. These disorders consisted of anxiety, mood, somatoform, adaptation, drug withdrawal and personality disorders. Nearly $93.22 \%$ of our patients, who had OLP, suffered from anxiety disorders, $52.54 \%$ suffered from mood disorders, $10.16 \%$ had somatoform disorders and $1.17 \%$ had personality disorders. Some patients had several concomitant psychiatric disorders. The most common disorder among our patients was generalized anxiety disorder (GAD) with a prevalence of $54.32 \%$; major depression disorder ranked second with a prevalence of $35.59 \%$ and only $5.08 \%$ of the patients did not have any psychiatric disorder, which is consistent with the results of a study carried out by Collela, who had observed a higher level of anxiety and depression in OLP patients compared to a control group (9). Chaudhary concluded from a study in 2004 that OLP patients have a higher level of stress, anxiety and depression compared to healthy individuals (11). The level of depression observed in our patients was comparable to the level observed by Akay, who reported depression in $53 \%$ of the patients suffering from OLP (4).

Another important consideration in the current study was the fact that in some patients the condition exacerbated regarding lesion size, form of the lesions, pain as soon as they were subjected to a certain kind of stress during the study period. Such stressors consisted of family members' disease, financial or legal problems, cancerophobia, and family disagreements (a second marriage of the husband, marriage of children despite parents' opposition, lack of understanding between spouses), loneliness, worries concerning childbirth, accidents, assault and battery and death of family members and relatives. However, some studies have demonstrated that stress may not result in OLP development but OLP may alter the individual's self-image and influence his/ her public relations and lead to secondary depression (4). Some other studies have failed to establish a direct cause-and-affect relationship between psychiatric disorders and lichen planus (6). In addition, although there seemed to be a parallel relationship between the general response to psychotherapy and the general response to OLP treatment in the case group, we were not able to substantiate this using Spearman's analysis of correlation coefficient.

Generally, it may be concluded that although the current study has failed to statistically and decisively establish 
the key role of psychotherapy, especially the drug therapy of these conditions, in the treatment of oral lichen planus, our observation concerning the exacerbation of the signs and symptoms of the lesions concomitant with stressful experiences of the patients during study period and the effect of psychotherapy in reduction of lesion size indicated that psychotherapy can be used, at least as an adjunct to routine OLP treatment, to minimize the use of topical and systemic corticosteroids, since topical corticosteroids have various local side effects, including oral candidiasis and xerostomia and widespread systemic side effects such as hypertension, tachycardia, peptic ulcer, gastritis, edema and an increase in appetite, restricting their use (12).

Studies on the effect of psychotherapy alone (drug therapy and non-drug therapy) on lichen planus lesions, personality assessment and determining stress level during examination may help determine the role of psychotherapy in this condition.

\section{Conclusion}

The present study on the effect of drug therapy of psychiatric disorders on OLP indicates that psychiatric treatment, along with routine OLP treatment, can be effective in reducing the size of the lesions. Therefore, psychiatric treatment of the patients along with routine treatment of oral lichen planus lesions, is recommended.

\section{References}

1. Martin S, Greenberg M. Red and White Lesions of Oral Mucosa. Burket's oral Medicine. BC Decker Inc: Spain; 2003. p.107-10.

2. Zakrzewska JM, Chan ES, Thornhill MH. A systematic review of placebo-controlled randomized clinical trials of treatments used in oral lichen planus. Br J Dermatol. 2005;153:336-41.

3. Zhao ZZ, Savage NW, Sugerman PB, Walsh LJ. Mast cell/T cell interactions in oral lichen planus. J Oral Pathol Med. 2002;31:18995.

4. Akay A, Pekcanlar A, Bozdag KE, Altintas L, Karaman A. Assessment of depression in subjects with psoriasis vulgaris and lichen planus. J Eur Acad Dermatol Venereol. 2002;16:347-52.

5. Allen CM, Beck FM, Rossie KM, Kaul TJ. Relation of stress and anxiety to oral lichen planus. Oral Surg Oral Med Oral Pathol. 1986;61:44-6.

6. Rojo-Moreno JL, Bagán JV, Rojo-Moreno J, Donat JS, Milián MA, Jiménez Y. Psychologic factors and oral lichen planus. A psychometric evaluation of 100 cases. Oral Surg Oral Med Oral Pathol Oral Radiol Endod. 1998;86:687-91.

7. Vallejo MJ, Huerta G, Cerero R, Seoane JM. Anxiety and depression as risk factors for oral lichen planus. Dermatology. 2001;203:303-7.

8. Sadock BJ, Sadock VA. Comprehensive textbook of psychiatry. ww co: Philadelphia; 2005. p.137, 2180.

9. Colella G, Gritti P, De Luca F, De Vito M. The psychopathological aspects of oral lichen planus (OLP). Minerva Stomatol. 1993;42:26570.

10. Carbone M, Goss E, Carrozzo M, Castellano S, Conrotto D, Broccoletti R, et al. Systemic and topical corticosteroid treatment of oral lichen planus: a comparative study with long-term follow-up. J Oral Pathol Med. 2003;32:323-9.

11. Chaudhary S. Psychosocial stressors in oral lichen planus. Aust Dent J. 2004;49:192-5.

12. Gage TW, Picket FA. Dental Drug Reference. Mosby Dompany: Piladelphia; 2003. p. 209,722. 